\title{
Governança Corporativa: um estudo bibliométrico da produção científica entre 2010 a 2016
}

\section{Corporate Governance: a bibliometric study of scientific production between 2010 and 2016}

\author{
RAFAEL MAXIMIANO FERREIRA* \\ SAMUEL LYNCON LEANDRO DE LIMA** \\ ADHMIR RENAN VOLTOLINI GOMES*** \\ GILMAR RIBEIRO DE MELLO****
}

\section{RESUMO}

A governança corporativa é composta de um conjunto de mecanismos que buscam maximizar a geração de valor, no longo prazo, para as empresas. No Brasil o tema ganha relevância e destaque acadêmico a partir do ano de 2006 em virtude da aprovação da Lei Sarbanes Oxley, em 2002 nos Estados Unidos da América (EUA). O propósito deste trabalho consistiu em avaliar a produção cientifica no Brasil sobre a temática governança corporativa para o período compreendido entre 2010 a 2016. Diante disso, realizou-se uma pesquisa bibliográfica e bibliométrica, tendo como base dados a base da Coordenação de Aperfeiçoamento de Pessoal de Nível Superior (Capes) e Scientific

* Universidade Estadual do Oeste do Paraná. Acadêmico do Programa de Pós-Graduação strictu sensu em Contabilidade - PPGC da UNIOESTE (Mestrado em Contabilidade). Atualmente é Professor Universitário da União Educacional de Cascavel (UNIVEL). rafamaxf@gmail.com .

** Universidade Estadual do Oeste do Paraná. Mestrando em Contabilidade pela Universidade Estadual do Oeste do Paraná - UNIOESTE. samuellynconleandro@gmail.com .

*** AUniversidade Estadual do Oeste do Paraná. Mestrando em Contabilidade pela Universidade Estadual do Oeste do Paraná - UNIOESTE. adhmir.renan@gmail.com ,

**** Universidade Estadual do Oeste do Paraná. Doutor e Mestre em Ciências Contábeis pela Universidade de São Paulo - FEA/USP. Editor Científico da revista Gestão e Desenvolvimento em Revista - G\&D em revista. Tem experiência na área de Contabilidade e Administração, com ênfase em Contabilidade Gerencial e Gestão Pública.

gilmarribeirodemello@gmail.com . 
Periodicals Electronic Library (Spell), com a aplicação das três Leis da bibliometria, sendo elas: Lei de Bradford, Lei de Lotka e Lei de Zipf, no intuito de analisar a disseminação das pesquisas sobre a temática. Os resultados apresentaram uma boa produção cientifica por periódicos, entretanto o presente estudo não conseguiu constatar a validação da Lei de Lotka, uma vez a produção se encontra bastante pulverizada. Além disso, a Lei de Zipf foi aplicada sobre os títulos e palavras-chave dos artigos que analisados, constatando-se que os termos governança corporativa, estrutura, análise e desempenho são alguns dos termos mais utilizados na produção cientifica estudada.

Palavras chave: Governança Corporativa, Bibliometria, Procedimento Metodológico, Teoria da Agência, Teoria da Divulgação.

\section{Abstract}

Corporate governance is composed of a set of mechanisms that seek to maximize the generation of value, in the long term, for companies. In Brazil the subject gained relevance and academic prominence from the year 2006 due to the approval of the Sarbanes Oxley Act in 2002 in the United States of America. The purpose of this research was to evaluate the scientific production in Brazil on the corporate governance theme for the period from 2010 to 2016. A bibliographical and bibliometric research was carried out, based on data from the Coordination of Improvement of Higher Education Personnel (Capes) and Scientific Periodicals Electronic Library (Spell), with the application of the three Laws of bibliometric; Law of Bradford, Law of Lotka and Law of Zipf, in order to analyze the dissemination of research on the subject. The results presented a good scientific production by periodicals, however the present study was not able to verify the validation of the Law of Lotka, once the production is very pulverized. In addition, the Zipf Law was applied on the titles and keywords of the articles analyzed, and it was found that the terms corporate governance, structure, analysis and performance are some of the most used terms in the scientific production studied.

Keywords: Corporate Governance, Bibliometric, Methodological Procedure, Agency Theory, Theory of Disclosure. 


\section{INTRODUÇÃo}

O tema governança corporativa está relacionado com o processo decisório que ocorre na alta gestão das organizações, sejam elas de capital aberto ou fechado, tendo como foco o relacionamento entre sócios, executivos e acionistas. A finalidade da governança corporativa está atrelada a possíveis conflitos de interesse, limitações cognitivas e técnicas, que podem vir a ocorrer dentro da alta administração das empresas. Neste contexto, ela é definida como o conjunto de mecanismos que busquem fazer com que as decisões da administração maximizem a geração de valor no longo prazo para a empresa (SILVEIRA, 2010).

A governança corporativa surge como um importante instrumento de melhoria na qualidade da gestão, administração e responsabilidade das organizações, de maneira a buscar que as organizações sejam mais eficientes (SOUZA; BAIDYA, 2016). O tema ganha destaque na área da pesquisa acadêmica no Brasil a partir do ano de 2006, como reflexo da promulgação da Lei Sarbanes Oxley, em 2002, nos Estados Unidos (RIBEIRO; SANTOS, 2015).

Neste contexto, a pesquisa é relevante, pois segundo Catapan e Cherobim (2010), tem-se a necessidade de uma abrangência mais extensa sobre a tratativa bibliométrica do tema governança corporativa, visto que alguns estudos têm delimitado o campo de pesquisa para a seleção de artigos, para posterior análise. O presente estudo segue a mesma vertente dos estudos de e Ribeiro et al. (2012); Ribeiro, Costa e Ferreira (2014); Ribeiro e Santos (2015), pelo fato de utilizar o ferramental da pesquisa bibliográfica e bibliométrica para investigar a produção cientifica sobre o tema governança corporativa.

Desta maneira, o estudo busca responder a seguinte pergunta: Qual o estágio do desenvolvimento da pesquisa em governança corporativa no Brasil, no período de 2010 a 2016?

Diante do exposto, o objetivo central desta pesquisa consiste em analisar o estágio do desenvolvimento da pesquisa sobre o tema governança corporativa no Brasil, considerando os artigos publicados no período de 2010 a 2016.

Com relação a delimitação desta pesquisa, os artigos analisados são originários das bases de dados Capes e Spell e dizem respeito ao período de 2010 a 2016, sendo que foram observadas as proprie- 
dades referentes a: quantidade de produção cientifica publicada; produtividade de artigos por periódico cientifico, por meio da Lei de Bradfort; produtividade de artigos por autor, por meio da Lei de Lotka; procedimento metodológico adotado para a pesquisa; e recorrência de palavras, por meio da Lei de Zipf. Estando desta forma embasada nas Leis clássicas da bibliometria.

Este artigo está estruturado em cinco seções, a primeira parte é apresentada a introdução. A segunda seção apresenta o referencial teórico referente ao tema governança corporativa, Teoria da Agência e Teoria da Divulgação. A terceira seção descreve os procedimentos metodológicos utilizados no desenvolvimento da pesquisa. $\mathrm{Na}$ sequência, a quarta seção apresenta os resultados encontrados. Por fim, na última sessão constam as considerações finais.

\section{REFERENCIAL TEÓRICo}

Nesta seção são abordados e discutidos os conceitos relacionados à Governança Corporativa e sua base conceitual, a Teoria da Agência e a Teoria da Divulgação.

\subsection{Governança Corporativa}

A governança corporativa pode ser definida como um conjunto de procedimentos sistemáticos que buscam reduzir custos relacionados a questões de agência. Nesse sentido, a governança corporativa possui um relacionamento vinculado ao desempenho das organizações, por intermédio das práticas de governança propostas, que dentre seus direcionamentos, possui uma abordagem com enfoque ao problema de agência, situação decorrente da medida em que os gestores tomam suas decisões aspirando maximizar seus interesses e propósitos particulares, em detrimento da tomada de decisões que possuem a finalidade de maximização da riqueza dos acionistas, objetivo pelo qual foram definitivamente contratados (SILVEIRA, 2004).

As discussões relacionadas com a temática da governança corporativa, no Brasil, iniciaram por volta dos anos de 1990, com algumas particularidades significativas no que diz respeito às organizações nacionais. Essas características marcantes se devem ao fato de que o contexto nacional em que as organizações estão inseridas, ainda em 
sua maioria é composto por empresas com o controle familiar, na qual representa uma relação de agência que precisa ser compreendida na perspectiva da expatriação dos acionistas minoritários pelos majoritários. É importante destacar, também, que a as pesquisas sobre a governança corporativa começam a ter um posicionamento considerável com o surgimento de organizações modernas, na qual permeiam o conflito de interesses (FERREIRA, 2012).

Durante décadas, a governança corporativa esteve presente no processo de gestão das organizações, desempenhando seu papel de modo satisfatório, especialmente naquelas classificadas como de capital aberto. No entanto, com o advento de escândalos relacionados a grandes organizações, como aqueles ocorridos com a Enron e a WorldCom, empresas norte-americanas e com suas respectivas empresas de auditoria, que até então desfrutavam de reconhecimento relevante a nível mundial, protagonizaram situações lamentáveis que de certa forma afetou negativamente o mercado de modo geral. Esses acontecimentos provocaram modificações no processo de gestão das organizações e, consequentemente, na governança corporativa (ROSSONI, 2009).

Ao adotarem as práticas propostas pela governança corporativa, independentemente de buscar como objetivo apenas o atendimento de normas institucionais, ou pela circunstância de estarem relacionadas em listagem específicas de ações, por meio dos níveis de governança da Bolsa de Valores, Mercadorias e Futuros de São Paulo (BM\&FBOVESPA), as organizações passam a se comportar de maneira mais atrativa, desfrutando de algumas vantagens, como por exemplo, a melhor acessibilidade na captação de recursos e, consequentemente, com um custo agregado menor. Nessa perspectiva, as vantagens evidentes, decorrentes da adoção das práticas da governança corporativa, uma vez que proporciona a redução dos custos relacionados ao capital, oportuniza a organização melhor desempenho, tendo como consequência a maximização do valor de mercado e rentabilidade (FERREIRA et al., 2013; CALDAS; TAMBOSI FILHO; VIEIRA, 2014).

A governança corporativa possui uma relação próxima com a Teoria da Agência, considerando que aquela busca dentre outros elementos primordiais para a gestão das organizações, minimizar os problemas de agência causados entre os agentes participantes 
das organizações (SILVEIRA, 2004), dado que essa explica a fundamentação desse relacionamento entre os indivíduos principal e agente, bem como os possíveis conflitos decorrentes dessa relação (LOPES; MARTINS, 2005). Dessa forma, considerando a relação entre os indivíduos participantes das organizações, na próxima seção é discutido sobre a teoria da agência.

\subsection{Teoria da Agência}

A abordagem mais eficiente, no sentido de conseguir a obtenção de dados da economia da informação, é compreender o contexto de um único indivíduo, e a partir desse pressuposto ampliar para dois indivíduos. Diante disso, um indivíduo é denominado de agente e outro indivíduo é definido como o principal (HENDRIKSEN; VAN BREDA, 1999). Os autores contribuem dizendo que o agente é responsável por realizar determinadas atividades para o principal, em troca dessas atividades prestadas, o principal tem a responsabilidade de remunerar o agente.

Lopes e Martins (2005) comentam que com o surgimento de organizações modernas, em que se entende distinção entre a propriedade e a gestão, cria-se uma situação extremamente delicada, ou seja, um cenário de conflito de interesses entre os investidores e os administradores, ou ainda, entre administradores de diferentes níveis das organizações. Diante disso, o enfoque da teoria da agência está fundamentado na perspectiva de que a organização é um conjunto de relações contratuais entre diversos agentes que possuem interesses distintos sobre suas atividades (STARKE JUNIOR; FREITAG; CROZZATI, 2006).

O maior causador dos conflitos de agência está relacionado à evidenciação das informações, na medida em que são evidenciadas de forma incompleta e os usuários dessas informações não conseguem satisfazer as suas necessidades, ocorre o problema denominado de assimetria informacionais (HENDRIKSEN; VAN BREDA, 1999). Nesse sentido, Lopes e Martins (2005) comentam que o cotidiano do cenário econômico trabalha com uma assimetria informacional muito grande entre os agentes, e que se não houvesse essa assimetria de informação não haveria utilidade para a contabilidade. Considerando a assimetria informacional, na seção seguinte são apresentados os principais aspectos relativos à teoria da divulgação. 


\subsection{Teoria da Divulgação}

A Teoria da Divulgação tem como objetivo explicar a motivação dos gestores de realizarem a divulgação de informações financeiras, bem como explicar as razões e apresentar os efeitos financeiro e econômico produzidos para a organização por intermédio dessa ação de divulgar informações específicas sobre conhecimento, até então, apenas da gestão da empresa (VERRECCHIA, 1983).

Nessa perspectiva, Salotti e Yamamoto (2007) propõem que uma empresa com boas condições financeiras, em um curto intervalo de tempo, possui essa situação como um fator positivo e, consequentemente, realizando a divulgação de uma informação relacionada a esse assunto poderá ser vista de uma maneira especial. No entanto, os respectivos autores pontuam que uma empresa que estiver posicionada de maneira desfavorável, em se tratando das finanças, poderá optar por não divulgar informações, que poderão ser recebidas negativamente pelo mercado.

É importante ressaltar, conforme explicam os autores Rufino e Monte (2015), que há duas vertentes de divulgação: a obrigatória e a voluntária. As divulgações obrigatórias possuem um padrão para serem elaboradas e, consequentemente, divulgadas, no entanto, as divulgações voluntárias estão relacionadas a variáveis endógenas da empresa, ou seja, estão sujeitas ao julgamento dos gestores por realizá-la ou não. Entretanto, a adoção e a prática da divulgação voluntária, proporciona uma riqueza de informações aos usuários, maximizando a transparência organizacional e minimizando a assimetria de informações, fator que provoca uma grande discussão no ambiente corporativo (FORTE et al., 2015).

Com isso, na seção subsequente são apresentados e detalhados os procedimentos metodológicos utilizados para o desenvolvimento da pesquisa.

\section{Procedimentos Metodológicos}

Tendo como objetivo responde a problematização apresentada, o objetivo deste estudo se classifica como descritivo (RAUPP; BEUREN, 2009; SILVA, 2010), pois objetivou-se descrever as características sobre a produção acadêmica sobre o tema governança corporativa. Para tanto, adotou-se técnicas de pesquisa bibliográfica 
e bibliométrica. A pesquisa bibliográfica possibilitou conhecer o material científico existente sobre o tema a ser tratado (SILVA, 2010), ao passo que a bibliometria possibilita a verificação dos aspectos quantitativos e a disseminação da pesquisa acerca da governança corporativa. A pesquisa possui uma abordagem qualitativa, explicada pela utilização de pesquisa bibliométrica com a utilização de análise de frequência para tratar os dados.

O universo de investigação compreendeu todos os artigos dos periódicos disponibilizados na base de dados da Coordenação de Aperfeiçoamento de Pessoal de Nível Superior (Capes) e Scientific Periodicals Electronic Library (Spell) na temática governança corporativa. A coleta de dados ocorreu no mês de novembro de 2016.

O processo de seleção dos artigos ocorreu da seguinte forma: a) seleção das palavras-chaves aplicadas nos filtros de pesquisa das bases de dados; b) coleta de dados nas bases de Periódicos Capes e Spell; c) seleção dos artigos, realizada por meio da leitura dos títulos e resumos. A palavra-chave utilizada para a seleção dos artigos científicos foi "governança corporativa" e optou-se no filtro da base dados para selecionar apenas artigos que contivessem em seus títulos a respectiva palavra-chave. O recorte temporal estipulado foi dos anos de 2010 a 2016. Foram selecionados somente artigos científicos em língua portuguesa, tendo em vista o objetivo de avaliar a produção nacional sobre a temática. Desta forma, resultou a coleta de 252 artigos científicos. Na sequência realizou-se a verificação dos artigos científicos repetidos, sendo encontrados 74, restando 178 artigos científicos na composição do estudo.

As categorias de análise se basearam nos estudos de Ferreira (2010) e Ribeiro e Santos (2015), que se utilizaram das três leis clássicas da bibliometria: Lei de Bradford, onde é mensurado o nível de relevância dos periódicos sobre a temática do estudo; Lei de Lotka, na qual será medida a produtividade dos autores através de um modelo de distribuição de tamanho-frequência, considerando aspectos de coautoria; e a Lei de Zipf, onde será evidenciada a quantidade de ocorrência das palavras verificadas no conteúdo das pesquisas científicas consideradas no trabalho.

A operacionalização da análise dos resultados alcançados, através da busca nas bases de dados, ocorreu com o auxílio do software Micro- 
soft Excel, no que se refere a tabulação, criação de gráficos, quadros e tabelas; e Wordle ${ }^{\mathrm{TM}}$, na criação da nuvem de palavras.

Como limitação de pesquisa salienta-se a palavra-chave escolhida e os filtros que foram utilizados na busca, bem como, o corte temporal que foi escolhido. A escolha das bases de dados Capes e Spell delimitam o alcance da presente pesquisa, o que pode conferir um viés para a pesquisa.

\section{Apresentação e Análise dos Resultados}

Esta seção dispõe da disseminação da produção acadêmica sobre o tema governança corporativa, no período de 2010 a novembro de 2016. Conduzida na seguinte ordem: distribuição da produção acadêmica ao longo do período estudado; produtividade por periódico (Lei de Bradford); produtividade dos autores (Lei de Lotka); característica da autoria; vínculo institucional dos autores; abordagem metodológica utilizada nas pesquisas; e frequência de palavras (Lei de Zipf).

A Figura 1 apresenta a número de artigos publicados sobre a governança corporativa, no período estabelecido, de forma a destacar o crescimento da pesquisa entre os anos de 2013, 2014 e 2015, apresentando $15 \%$, $24 \%$ e $21 \%$, respectivamente, com seu posterior decréscimo no ano de 2016. Destaca-se o fato de a pesquisa sobre o tema ter ganho espaço na academia brasileira desde o ano 2002, por ocasião da promulgação da Lei Sarbanes Oxley, nos Estados Unidos, apresentando uma evolução mais acentuada a partir do ano de 2006 (RIBEIRO; SANTOS, 2015).

A Lei de Bradford diz respeito a dispersão de artigos em termos de variáveis de proximidade ou afastamento (ARAÚJO, 2006), permite desta maneira estimar o grau de produtividade de periódicos (GUEDES; BORSCHIVER, 2005), indicando quais os periódicos mais produtivos sobre determinado assunto (FERREIRA, 2010). Esta lei possibilita a criação das três zonas de distribuição e classificação de periódicos. Na zona de classificação A estão elencados os periódicos mais produtivos e nas zonas B e C são definidas a partir do multiplicador de Bradfort; tal construção pode ser verificada na Tabela 1. 
Figura 1 - Evolução das pesquisas em governança corporativa

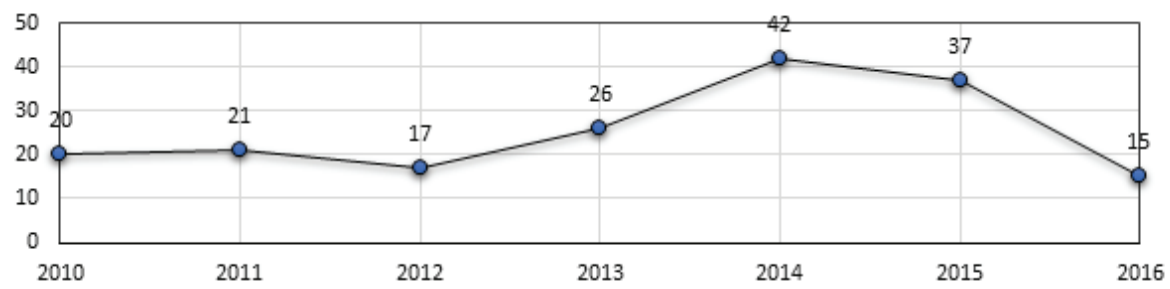

Fonte: Dados da pesquisa.

\section{Tabela 1 - Distribuição ideal de Bradford}

\begin{tabular}{l|l|l|l|l}
\hline $\begin{array}{l}\text { Zonas de } \\
\text { Classificação }\end{array}$ & $\begin{array}{l}\text { Fator de } \\
\text { multiplicação }\end{array}$ & Periódicos & $\begin{array}{l}\text { Produtividade } \\
\text { de artigos }\end{array}$ & $\%$ de artigos \\
\hline A & & 23 & 119 & $66,85 \%$ \\
\hline B & 2,28 & 52,44 & 42 & $23,60 \%$ \\
\hline C & 2,28 & 119,56 & 17 & $9,55 \%$ \\
\hline Total & - & - & 178 & $100 \%$ \\
\hline
\end{tabular}

Fonte: Dados da pesquisa

A Tabela 1 apresenta as zonas de classificação dos periódicos, sendo que estes são determinados a partir da produção de artigos científicos e de sua concentração em periódicos. Os periódicos da zona de classificação A correspondem a concentração; a zona B corresponde a produção média e a zona $C$ corresponde aos periódicos de baixa produtividade. A lei de Bradfort sugere que na medida em que surgem artigos sobre um novo assunto emergem eventualmente um núcleo de periódicos que publicam sobre o tema, o que corresponde aos periódicos mais produtivos sobre o tema, sendo a Zona A correspondente a $1 / 3$ do total de periódicos e as Zona B e C são definidas a partir do fator de multiplicação sobre o resultado da Zona A e respectivamente sobre a Zona B (LOUSADA et al., 2012).

A respeito dos periódicos que concentram publicações sobre governança corporativa, foram identificados 69 periódicos. As informações da disseminação dos artigos sobre o tema, conforme a Lei de Bradford, são apresentadas na Tabela 2. 
Ao se analisar os resultados é possível verificar que a condição de maior concentração de trabalhos, em um número menor de periódicos e um maior número de periódicos com poucos trabalhos, conforme proposta na Lei de Bradford, ocorreu para a presente pesquisa. É exequível constatar que as zonas de concentração são heterogêneas, visto que a Zona A abrange vinte e três periódicos, a Zona $\mathrm{B}$ concentra vinte e nove periódicos e a Zona $\mathrm{C}$ abarca vinte e sete periódicos. Com tais resultados é possível proceder com a classificação, por meio das zonas de classificação: concentração, produtividade média e baixa produtividade, que são propostas pela Lei de Bradford.

Quando se analisa a quantidade de artigos publicados nos periódicos científicos é possível verificar que $66,85 \%$ da produção se encontra na Zona A: Concentração. Destaca-se o fato de 6 (seis) periódicos concentrarem $30,90 \%$ da produção para o período que foi alvo da análise (8,7\% da população de periódicos), sendo elas: Revista Contemporânea de Contabilidade (14 artigos), REGE - Revista de Gestão (10 artigos), Contabilidade, Gestão e Governança (9 artigos), Revista Contabilidade e Finanças - USP (8 artigos), BASE - Revesta de Administração e Contabilidade da Unisinos (7 artigos) e Revista de Gestão, Finanças e Contabilidade (7 artigos).

A produção científica restante $(32,02 \%)$ se encontra pulverizada nos 46 periódicos restantes, sendo que cada periódico conta com apenas um ou dois artigos sobre o assunto, cabe destacar que tais periódicos representam $66,67 \%$ do total de 69 periódicos localizados, o que demonstra o grau de amadurecimento da governança corporativa no Brasil. 
Tabela 2 - Produtividade de periódicos conforme a Lei de Bradford

\begin{tabular}{|c|c|c|c|c|}
\hline Periódicos & $\begin{array}{l}\text { N. de } \\
\text { artigos }\end{array}$ & $\begin{array}{l}\% \text { de } \\
\text { artigos }\end{array}$ & $\begin{array}{l}\text { Frequência } \\
\text { acumulada }\end{array}$ & $\begin{array}{l}\text { Áreas de } \\
\text { dispersão }\end{array}$ \\
\hline Revista Contemporânea de Contabilidade (RCC) & 14 & $7,87 \%$ & $7,87 \%$ & \multirow{23}{*}{$\begin{array}{c}\text { Zona A: } \\
\text { Concentração }\end{array}$} \\
\hline REGE - Revista de Gestão & 10 & $5,62 \%$ & $13,48 \%$ & \\
\hline Contabilidade, Gestão e Governança & 9 & $5,06 \%$ & $18,54 \%$ & \\
\hline Revista Contabilidade e Finanças - USP & 8 & $4,49 \%$ & $23,03 \%$ & \\
\hline $\begin{array}{l}\text { BASE - Rev. de Adm. e Contabilidade da } \\
\text { Unisinos }\end{array}$ & 7 & $3,93 \%$ & $26,97 \%$ & \\
\hline Revista de Gestão, Finanças e Contabilidade & 7 & $3,93 \%$ & $30,90 \%$ & \\
\hline Revista Universo Contábil & 6 & $3,37 \%$ & $34,27 \%$ & \\
\hline Enfoque: Reflexão Contábil & 5 & $2,81 \%$ & $37,08 \%$ & \\
\hline RACE - Ver. de Adm., Contabilidade e Economia & 5 & $2,81 \%$ & $39,89 \%$ & \\
\hline Revista de Administração FACES Journal & 5 & $2,81 \%$ & $42,70 \%$ & \\
\hline Advances in Scientific and Applied Accounting & 4 & $2,25 \%$ & $44,94 \%$ & \\
\hline Organizações em Contexto & 4 & $2,25 \%$ & $47,19 \%$ & \\
\hline Revista Contabilidade Vista \& Revista & 4 & $2,25 \%$ & $49,44 \%$ & \\
\hline Revista de Administração da UFMS & 4 & $2,25 \%$ & $51,69 \%$ & \\
\hline Revista de Administração Mackenzie & 4 & $2,25 \%$ & $53,93 \%$ & \\
\hline Revista de Ciências da Administração & 4 & $2,25 \%$ & $56,18 \%$ & \\
\hline Gestão \& Regionalidade & 3 & $1,69 \%$ & $57,87 \%$ & \\
\hline $\begin{array}{l}\text { Revista Catarinense da Ciência Contábil - } \\
\text { CRCSC }\end{array}$ & 3 & $1,69 \%$ & $59,55 \%$ & \\
\hline Revista de Administração Pública (RAP) & 3 & $1,69 \%$ & $61,24 \%$ & \\
\hline Revista Economia e Gestão & 3 & $1,69 \%$ & $62,92 \%$ & \\
\hline Revista Gestão Organizacional & 3 & $1,69 \%$ & $64,61 \%$ & \\
\hline BBR Brazilian Business Review & 2 & $1,12 \%$ & $65,73 \%$ & \\
\hline $\begin{array}{l}\text { Caderno Profissional de Administração - } \\
\text { UNIMEP }\end{array}$ & 2 & $1,12 \%$ & $66,85 \%$ & \\
\hline Gestão \& Planejamento & 2 & $1,12 \%$ & $67,98 \%$ & \\
\hline Organizações Rurais \& Agroindustriais & 2 & $1,12 \%$ & $69,10 \%$ & \\
\hline Pensar contábil & 2 & $1,12 \%$ & $70,22 \%$ & \\
\hline Perspectivas em Gestão \& Conhecimento & 2 & $1,12 \%$ & $71,35 \%$ & \\
\hline RAC - Ver.. de Administração Contemporânea & 2 & $1,12 \%$ & $72,47 \%$ & \\
\hline REUNA & 2 & $1,12 \%$ & $73,60 \%$ & \\
\hline $\begin{array}{l}\text { REUNIR - Rev. de Adm., Cont. e } \\
\text { Sustentabilidade }\end{array}$ & 2 & $1,12 \%$ & $74,72 \%$ & \\
\hline Revista Brasileira de Gestão de Negócios & 2 & $1,12 \%$ & $75,84 \%$ & \\
\hline
\end{tabular}




\begin{tabular}{|c|c|c|c|c|}
\hline $\begin{array}{l}\text { Revista de Educação e Pesquisa em } \\
\text { Contabilidade }\end{array}$ & 2 & $1,12 \%$ & $76,97 \%$ & \multirow{21}{*}{$\begin{array}{l}\text { Zona B: } \\
\text { Produtividade } \\
\text { média }\end{array}$} \\
\hline Revista de Finanças Aplicadas & 2 & $1,12 \%$ & $78,09 \%$ & \\
\hline Revista de Negócios & 2 & $1,12 \%$ & $79,21 \%$ & \\
\hline Revista Evidenciação Contábil \& Finanças & 2 & $1,12 \%$ & $80,34 \%$ & \\
\hline Revista Sociedade, Contabilidade e Gestão & 2 & $1,12 \%$ & $81,46 \%$ & \\
\hline APGS & 1 & $0,56 \%$ & $82,02 \%$ & \\
\hline Contaduría y Administración & 1 & $0,56 \%$ & $82,58 \%$ & \\
\hline ConTexto & 1 & $0,56 \%$ & $83,15 \%$ & \\
\hline $\begin{array}{l}\text { CONTEXTUS - Rev. Contem. de Economia e } \\
\text { Gestão }\end{array}$ & 1 & $0,56 \%$ & $83,71 \%$ & \\
\hline $\begin{array}{l}\text { GEPROS. Gestão da Produção, Operações e } \\
\text { Sistemas }\end{array}$ & 1 & $0,56 \%$ & $84,27 \%$ & \\
\hline INTERNEXT & 1 & $0,56 \%$ & $84,83 \%$ & \\
\hline Organizações e Sociedade & 1 & $0,56 \%$ & $85,39 \%$ & \\
\hline PODIUM Sport, Leisure and Tourism Review & 1 & $0,56 \%$ & $85,96 \%$ & \\
\hline RAE - Revista de Administração de Empresas & 1 & $0,56 \%$ & $86,52 \%$ & \\
\hline RAIMED - Revista de Administração IMED & 1 & $0,56 \%$ & $87,08 \%$ & \\
\hline RAP - Revista de Administração Pública & 1 & $0,56 \%$ & $87,64 \%$ & \\
\hline READ - Revista Eletrônica de Administração & 1 & $0,56 \%$ & $88,20 \%$ & \\
\hline $\begin{array}{l}\text { Relatórios De Pesquisa Em Engenharia De } \\
\text { Produção }\end{array}$ & 1 & $0,56 \%$ & $88,76 \%$ & \\
\hline Revista Brasileira de Finanças & 1 & $0,56 \%$ & $89,33 \%$ & \\
\hline Revista de Administração MADE & 1 & $0,56 \%$ & $89,89 \%$ & \\
\hline Revista Contabilidade e Organizações & 1 & $0,56 \%$ & $90,45 \%$ & \\
\hline Revista da Universidade Vale do Rio Verde & 1 & $0,56 \%$ & $91,01 \%$ & \\
\hline Revista de Administração da UNIMEP & 1 & $0,56 \%$ & $91,57 \%$ & \\
\hline Revista de Administração de Roraima & 1 & $0,56 \%$ & $92,13 \%$ & \\
\hline Revista de Contabilidade e Controladoria & 1 & $0,56 \%$ & $92,70 \%$ & \\
\hline Revista de Contabilidade e Organizações & 1 & $0,56 \%$ & $93,26 \%$ & \\
\hline Revista de Economia e Administração & 1 & $0,56 \%$ & $93,82 \%$ & \\
\hline Revista de Gestão e Secretariado & 1 & $0,56 \%$ & $94,38 \%$ & \\
\hline Rev. Elet. de Ciência Administrativa (RECADM) & 1 & $0,56 \%$ & $94,94 \%$ & \\
\hline Revista Eletrônica de Estratégia \& Negócios & 1 & $0,56 \%$ & $95,51 \%$ & haixa \\
\hline Revista Eletrônica de Sistemas de Informação & 1 & $0,56 \%$ & $96,07 \%$ & \\
\hline Revista Estudos do CEPE & 1 & $0,56 \%$ & $96,63 \%$ & \\
\hline Revista Gestão \& Tecnologia & 1 & $0,56 \%$ & $97,19 \%$ & \\
\hline Revista GUAL & 1 & $0,56 \%$ & $97,75 \%$ & \\
\hline Revista Ibero-Americana de Estratégia - RIAE & 1 & $0,56 \%$ & $98,31 \%$ & \\
\hline Revista RAUNP & 1 & $0,56 \%$ & $98,88 \%$ & \\
\hline Revista TECER & 1 & $0,56 \%$ & $99,44 \%$ & \\
\hline RGSA - Revista de Gestão Social e Ambiental & 1 & $0,56 \%$ & $100,00 \%$ & \\
\hline Total Geral & 178 & $100,00 \%$ & - & - \\
\hline
\end{tabular}

Fonte: Dados da pesquisa 
A Lei de Lotka permite realizar uma análise sobre a produtividade de autores que escrevem sobre determinado tema. Segundo Ferreira (2010), uma larga proporção da literatura científica é produzida por um pequeno número de autores e um grande número de autores possui pouca produção científica. A produtividade individual dos autores que fazem parte da presente pesquisa é demonstrada na Tabela 3.

Os preceitos da Lei de Lotka estabelecem que alguns pesquisadores publicam muito e muitos publicam pouco (GUEDES; BORSCHIVER, 2005), nesse sentido os resultados obtidos não vão ao encontro dos preceitos dessa lei, visto que a produtividade não é gradualmente distribuída. A Tabela 3 demonstra que somente 98 autores possuem mais que uma publicação sobre o tema governança corporativa, e somente 4 autores possuem mais que cinco publicações, sendo que duzentos e oitenta e sete autores possuem apenas uma publicação sobre o tema.

Tabela 3 - Quantidade de publicações por autor

\begin{tabular}{l|l|l}
\hline N. de artigos publicados & Autores & $\%$ dos autores \\
\hline 11 & 1 & $0,26 \%$ \\
\hline 10 & 0 & $0,00 \%$ \\
\hline 9 & 0 & $0,00 \%$ \\
\hline 8 & 0 & $0,00 \%$ \\
\hline 7 & 1 & $0,26 \%$ \\
\hline 6 & 2 & $0,52 \%$ \\
\hline 5 & 2 & $0,52 \%$ \\
\hline 4 & 7 & $1,82 \%$ \\
\hline 3 & 18 & $4,68 \%$ \\
\hline 2 & 67 & $17,40 \%$ \\
\hline 1 & 287 & $74,55 \%$ \\
\hline Total & 385 & $100,00 \%$ \\
\hline
\end{tabular}

Fonte: Dados da pesquisa.

A Figura 2 demonstra as autorias dos 178 artigos publicados, onde constata-se que $94,38 \%$ dos artigos publicados são de autoria 
em parceria, sendo que os artigos de três e quatro autores são predominantes, corroborando com os resultados alcançados por Ribeiro e Santos (2015), permitindo desta maneira confirmar a existência de grupos de pesquisa sobre o tema no Brasil.

Figura 2 - Característica de autoria

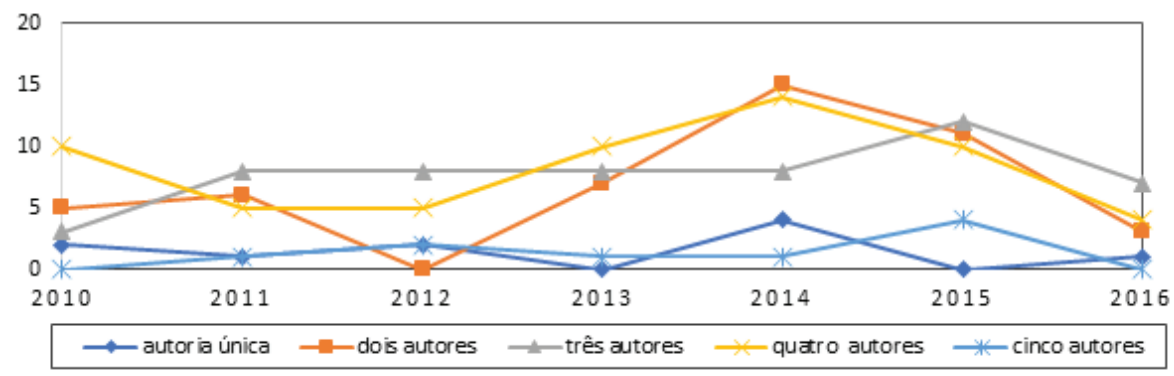

Fonte: Dados da pesquisa.

A Figura 3 destaca os autores que possuem maior produção sobre o tema, com destaque para: Henrique César Melo Ribeiro com 11 artigos; Márcia Martins Mendes de Luca com 7 artigos; Alessandra Carvalho de Vasconcelos e Hudson Fernandes Amaral, com 6 publicações cada; e Fernanda Maciel Peixoto e Geovanne Dias de Moura com 5 artigos cada.

Figura 3 - Produção por autor

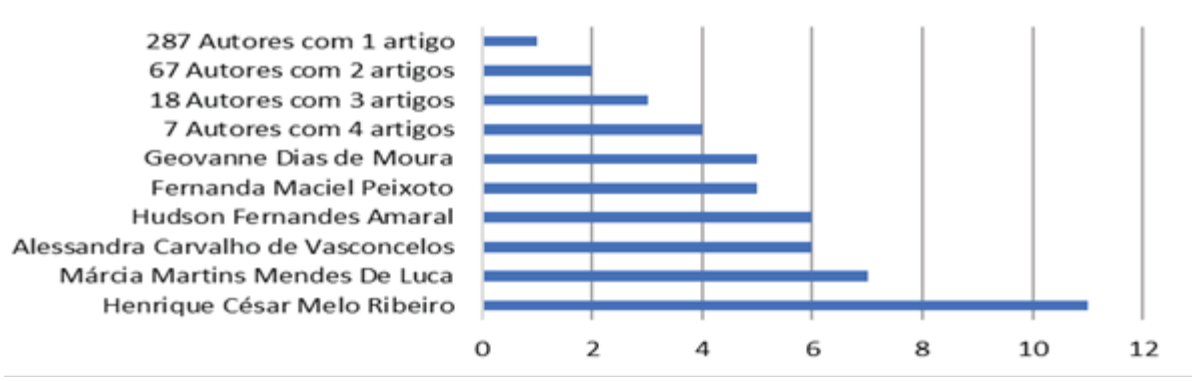

Fonte: Dados da pesquisa.

Com relação ao vínculo institucional dos autores, foram identificadas 90 Instituições de Ensino Superior (IES), as quais os autores estão vinculados. A Figura 4 demonstra que 7 instituições detêm vínculo com $67,53 \%$ dos autores identificados pela presente pesquisa, 
desta maneira é importante destacá-las: UFC (63 autores), USP (50 autores), FURB (49 autores), UNINOVE (32 autores), UFPR (24 autores), PUC-PR (22 autores) e UFMG (20 autores). Desta forma, o presente estudo confirma os resultados encontrados por Ribeiro e Santos (2015), tornando evidente também a existência de grupos de pesquisa sobre o tema governança corporativa nestas instituições.

Figura 4 - Quantidade de autores por vínculo com IES'S

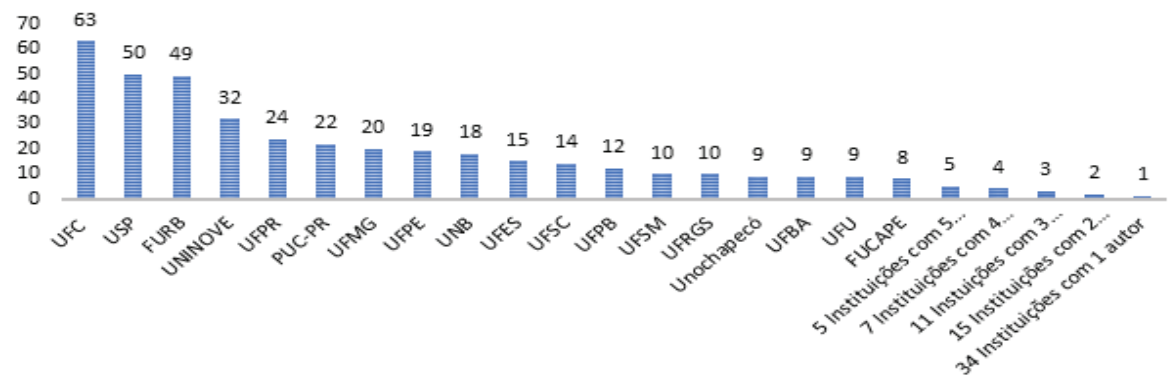

Fonte: Dados da pesquisa.

No que tange as abordagens metodológicas utilizadas para a elaboração das pesquisas, constatou-se predominância da abordagem quantitativa, visto que a mesma foi utilizada em $71,35 \%$ dos artigos localizados (127 artigos), frente a aplicação de $26,97 \%$ da abordagem qualitativa e $1,68 \%$ da abordagem quali-quanti nas pesquisas. A Figura 5 apresenta a utilização das abordagens durante o período alvo do estudo, de forma a destacar que a partir de 2011 a abordagem quantitativa foi mais utilizada na elaboração das pesquisas.

Figura 5 - Distribuição da abordagem metodológica utilizada

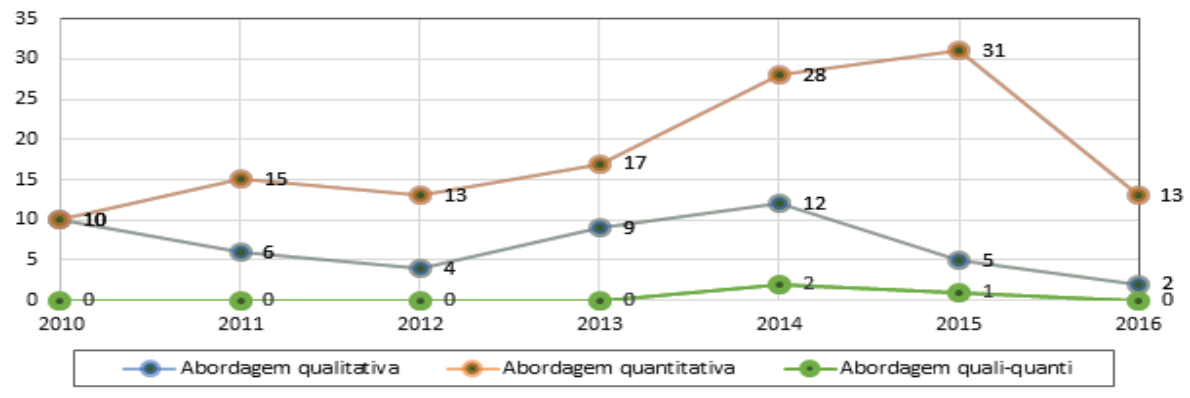

Fonte: Dados da pesquisa. 
É interessante destacar que a pesquisa descritiva foi a mais amplamente utilizada, estando presente em $62,92 \%$ das pesquisas. Com relação a abordagem qualitativa o estudo de caso, foi o tipo de pesquisa que teve maior destaque, para os estudos que adotaram a abordagem quantitativa a utilização de dados em painel foi o que apresentou maior relevância.

Com relação a verificação da aplicação da Lei de Zipf, que trata da frequência de ocorrência das palavras (Ferreira, 2010), assim como no estudo de Ribeiro e Santos (2015), se procedeu a elaboração da nuvem de palavras para verificar quais os principais termos foram utilizados nos títulos e palavras-chave dos 178 artigos.

Observa-se na Figura 6, que as palavras mais destacadas são governança corporativa, estrutura, mercado, teoria, desempenho, empresas, análise, agência e capital. A ocorrência com frequência destes termos leva ao entendimento que estes são os temas que estão sendo tratados nos trabalhos científicos que compuseram o estudo.

Figura 6 - Frequência de ocorrência de palavras nos títulos e palavras-chave

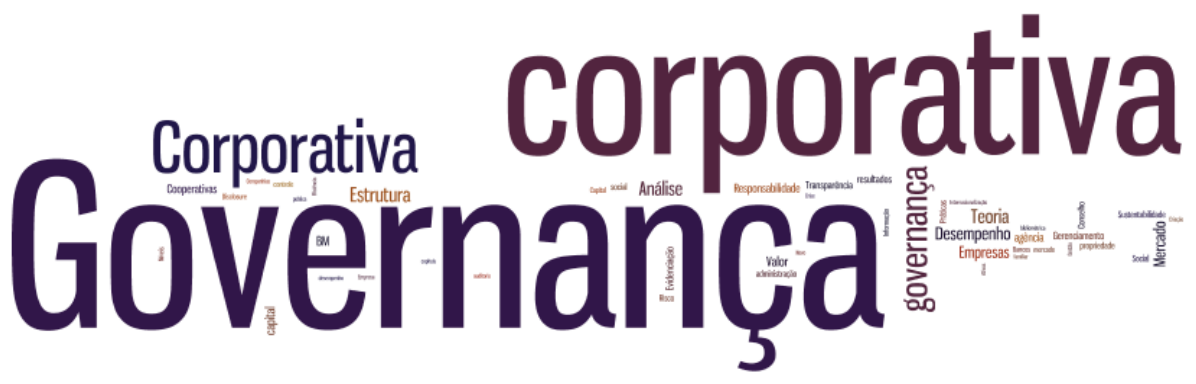

Fontes: Dados da pesquisa.

\section{Considerações finais}

O presente estudo buscou verificar o estágio do desenvolvimento da pesquisa em governança corporativa no período de 2010 a novembro de 2016 no Brasil. Para alcançar tal objetivo, a produção científica foi abordada da seguinte maneira: quantidade de produção cientifica publicada; produtividade de artigos por periódico científico, por meio da Lei de Bradfort; produtividade de artigos por autor, 
por meio da Lei de Lotka; recorrência de palavras, por meio da Lei de Zipf; e identificação dos procedimentos metodológicos adotado para a elaboração das pesquisas sobre a temática.

O tema governança corporativa, conforme discutido no referencial teórico é um tema relevante para a área empresarial e consequentemente para a área científica, desta maneira realizar uma avaliação sobre os níveis de produção é válido. Ao se realizar as análises através das Leis clássicas da bibliometria foi possível verificar que a produtividade dos periódicos nacionais vai ao encontro da Lei de Bradford, visto que há concentração de publicações em um grupo de periódicos.

Entretanto, com relação a produtividade por autor, a Lei de Lotka não é amplamente atendida, visto que a produção é pulverizada e do total de 385 autores encontrados com a pesquisa, somente 98 autores possuem mais do que uma publicação sobre a temática. No que tange os procedimentos metodológicos utilizados, constatouse a utilização da abordagem quantitativa como sendo principal procedimento utilizado.

Por meio dos resultados deste estudo, tendo como base as Leis clássicas da bibliometria, permite concluir que o material de pesquisa disponível sobre a governança corporativa no Brasil é acentuado, pela quantidade de publicações e de periódicos que publicam sobre esta temática, entretanto falta aprofundamento por parte dos autores, visto que $74,55 \%$ dos autores identificados escreveram somente uma vez sobre governança corporativa.

A continuidade pela discussão deve ser estimulada. Recomendase para futuros estudos, a ampliação das palavras-chaves utilizadas no filtro das pesquisas; e a ampliação das bases de dados para a seleção da produção cientifica, bem como a exploração de novas perspectivas que possibilitem o aprofundamento do tema.

\section{REFERÊNCIAS}

ARAÚJO, C. A. Bibliometria: evolução histórica e questões atuais. Em questão, v. 12, n. 1, 2006.

CALDAS, C. B.; TAMBOSI FILHO, E.; VIEIRA, A. M. Governança Corporativa e Sustentabilidade: uma relação necessária. Revista UNIABEU, v. 7, p. 353-369, 2014. 
CATAPAN, A.; CHEROBIM, A. P. M. S. Estado da arte da governança corporativa: estudo bibliométrico nos anos de 2000 a 2010. RACE-Revista de Administração, Contabilidade e Economia, v. 9, n. 1-2, p. 207-230, 2010.

FERREIRA, A. G. C. Bibliometria na avaliação de periódicos científicos. DataGramaZero-Rio de Janeiro, v. 11, n. 3, p. 1-9, 2010.

FERREIRA, R. N. Governança corporativa e desempenho: uma análise em empresas brasileiras de capital aberto. 2012. Tese de doutorado, Universidade Federal de Lavras, Lavras.

FERREIRA, R. N. et al. (2013). Governança corporativa, eficiência, produtividade e desempenho. RAM. Revista de Administração Mackenzie, v. 14, n. 4, 2013.

FORTE, L. M. et al. Determinants of voluntary disclosure: a study in the brazilian banking sector. Revista de Gestão, Finanças e Contabilidade, v. 5, n. 2, p. 23-37, 2015.

GUEDES, V. L. S., BORSCHIVER, S. Bibliometria: Uma ferramenta estatística para a gestão da informação e do conhecimento, em sistemas de informação, de comunicação e de avaliação científica e tecnológica. Anais do Encontro Nacional de Ciência da Informação, Salvador, 2005.

LOUSADA, M. et al. (2012). Produção científica sobre gestão do conhecimento e gestão da informação no âmbito da ciência da informação: uma aplicação da Lei de Bradford. Anales de Documentación, v. 15, n. 2, p. 01-17.

HENDRIKSEN, E. S.; VAN BREDA, M. F. Teoria da contabilidade. São Paulo: Atlas, 1999.

STARKE JUNIOR, P. C.; FREITAG, V. C.; CROZATTI, J. A função social da pesquisa em contabilidade. Anais do II Seminário de Ciências Contábeis de Blumenau, Blumenau, 2006.

LOPES, A. B.; MARTINS, E. Teoria da Contabilidade. São Paulo: Atlas, 2005.

RIBEIRO, H. C. M. et. al. Produção científica sobre os temas Governança Corporativa e Stakeholders em periódicos internacionais. Contabilidade, Gestão e Governança, v. 17, n. 1, p. 95-114, 2014.

RIBEIRO, H. C. M. et al. (2012). Governança corporativa: um estudo bibliométrico da produção cientifica das dissertações e teses. Contabilidade, Gestão e Governança, v. 15, n. 3, p. 52-70.

RIBEIRO, H. C. M.; SANTOS, M. C. Perfil e Evolução da Produção Científica do Tema Governança Corporativa nos periódicos Qualis/Capes Nacionais: Uma Análise Bibliométrica e de Redes Sociais. Contabilidade, Gestão e Governança, v. 18, n. 3, p. 4-27, 2015.

ROSSONI, L. Governança corporativa, legitimidade e desempenho das organizações listadas na Bovespa. 2009. Tese de doutorado, Universidade Federal do Paraná, Curitiba.

RUFINO, M. A.; MONTE, P. A. Fatores que Explicam a Divulgação Voluntária das 100 Empresas com Ações Mais Negociadas na BM\&FBovespa. Sociedade, Contabilidade e Gestão, v. 9, n. 3, p. 59-75, 2014.

SALOTTI, B. M.; YAMAMOTO, M. M. Divulgação voluntária da demonstração dos fluxos de caixa no mercado de capitais Brasileiro. Revista Contabilidade e Finanças, v. 19, n. 48, p. $37-49,2008$. 
SILVA, A. C. R. Metodologia da pesquisa aplicada à contabilidade: orientações de estudos, projetos, artigos, relatórios, monografias, dissertações, teses. São Paulo: Atlas, 2010.

SILVEIRA, A. M. Governança corporativa e estrutura de propriedade: determinantes e relação com o desempenho das empresas no Brasil. (2004). Tese de doutorado, Universidade de São Paulo, São Paulo.

SILVEIRA, A. M. Governança corporativa no Brasil e no mundo: teoria e prática. Rio de Janeiro: Elsevier, 2010.

SOUZA, F. P.; BAIDYA, T. K. N. Governança corporativa na Agência Nacional de Telecomunicações (ANATEL) como mecanismo de aperfeiçoar a gestão na Agência. Sociedade, Contabilidade e Gestão, v. 11, n. 1, p. 66-83, 2016.

VERRECCHIA, R. E. Discretionary Disclosure. Journal of Accounting and Economics, v. 5, p. 179-194, 1983.

Recebido em: 19-2-2018

Aprovado em: 22-11-2018

Avaliado pelo sistema double blind review.

Editor: Coordenação do PPGA/UMESP

Disponível em http://mjs.metodista.br/index.php/roc 